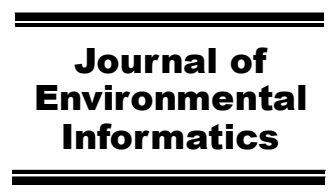

www.iseis.org/jei

\title{
Ocean Observation with Opto-Microfluidic Devices
}

\author{
D. Zhang, L. Men, and Q. Chen* \\ Department of Physics and Physical Oceanography, Memorial University of Newfoundland, St. John's, NL A1B 3X7, Canada
}

Received 02 April 2015; revised 22 November 2015; accepted 26 November 2015; published online 27 December 2016

\begin{abstract}
The success of ocean observation relies on effective monitoring technologies with increased functionalities, minimized size, and reduced cost. In this study, opto-microfluidic devices for sensing the salinity and temperature of sea water are proposed and demonstrated, which can be prepared with ultrafast laser fabrication and two-photon polymerization techniques. By applying femtosecond lasers as a powerful tool to achieve laser microfabrication with unprecedented high precision and quality, a Mach-Zehnder interferometer (MZI) has been fabricated and integrated into a microchannel as a miniaturized opto-microfluidic system. When the temperature changes or different saline solutions are introduced to the microchannel, different phase shifts in the MZI can be induced. The sensitivities of salinity and temperature have been found to be $215.744 \mathrm{~nm} / \mathrm{RIU}$ and $0.519 \mathrm{~nm} /{ }^{\circ} \mathrm{C}$ for the opto-microfluidic systems developed in this study. Considering the impact of the temperature perturbation to the phase shift, temperature calibration is proposed for a precise salinity measurement. The results demonstrate the practicability of opto-microfluidic devices for real-time salinity and temperature monitoring of sea water in harsh environment.
\end{abstract}

Keywords: opto-microfluidics, salinity, sea water, sensor, temperature

\section{Introduction}

Ocean is one of the most important ecologies on the earth which is crucial for the daily activities of human being. To preserve natural environment, environmental monitoring, including the measurement of water properties, must be carried out constantly (Shen et al., 2015; Urquhart et al., 2015; Forsythe et al., 2015; Xiao et al., 2015; Tan et al., 2015). Among different properties of oceans, temperature and salinity of sea water are two of the most important parameters for monitoring ocean currents, weather, iceberg floating, and oil pollution, which are critical for fishing, navigation, and human health. Various mechanical and electronic gauges have been fabricated using different techniques to achieve simultaneous measurement of different parameters. For example, the conductivity, temperature, and depth sensor (CTD) is a popular electronic instrument to measure the physical properties of seawater (Lawson et al., 2001). The gigantic volume of the testing equipment increases the energy consumption and cost. Fiberoptic sensors to achieve temperature and salinity measurement of seawater have been reported. The sensing elements mostly adopted fiber Bragg gratings (FBGs) (Shu et al., 2001; Men et al., 2008) and long period fiber gratings (LPGs) (Li et al., 2001; Wang et al., 2006), Mach-Zehnnder interferometer (MZI) (Tian et al., 2008; Wang et al., 2010),

\footnotetext{
${ }^{*}$ Corresponding author. Tel.: +1 709 8648878; fax: +1 7098648739 .

E-mail address: qiyingc@mun.ca (Q.Chen).
}

ISSN: 1726-2135 print/1684-8799 online

C 2016 ISEIS All rights reserved. doi:10.3808/jei.201600351
Fabry-Perot (FP) interferometer (Choi et al., 2010; Nguyen et al., 2011) and Michelson interferometer (Yuan et al., 2000). These fiber-optic sensing technologies exhibit significant advantages of flexibility and low fabrication cost. However, low salinety sensitivity of fiber sensors poses a major challenge for many applications. Therefore, design and fabrication of inexpensive, high-sensitive, miniaturized, and real-time sensors for oceanographic measurements are the most pressing demands.

Opto-microfluidics is a novel diagnostic technique which integrates optical components and microchannels on a palmsize chip to realize one or several measurements (Zhang et al., 2011). The significant advantages of opto-microfluidic sensors are portability, efficiency, sensitivity, versatile functionalities, compactness, minimized waste, and low cost. In these optomicrofluidic sensors, functional micro-optical structures are integrated with microchannels. The analyte in the microchannel interacts with the structures to generate different output signals. The reported micro-optical structures include diffraction grating (Schueller et al., 1999; Yu et al., 2010), MZI (Dumais et al., 2008; Crespi et al., 2010; Lapsley et al., 2011), roring resonance (Dai, 2009; Yebo et al., 2010, Zhang et al., 2011, Ren et al., 2012), surface plasmon resonance (Homola et al., 1997; Eftekhari et al., 2009), and LPG (Lor et al., 2005; Chin et al., 2008). Opto-microfluidics has been increasingly recognized as powerful technologies to realize environmental monitoring, biological analyses, and chemical syntheses.

In this paper, we report a waveguide-MZI based optomicrofluidic device for temperature and refractive index (RI) salinity measurement. By applying femtosecond lasers micro- 
fabrication technique in a photoresist material, a waveguide with a discontinuous core is fabricated and integrated into a microchannel as a miniaturized opto-microfluidic system. When the temperature or RI of the liquid in the microchannel varies, different phase shifts in the MZI allow determination of the salinity or temperature of the solution from the output spectra and light intensities of the MZI. According to the effect of the temperature and refractive index on the peak shift, accurate measurement of sea water salinity can be achieved.

\section{Materials and Methods}

\subsection{Principles of Sensing}

The Mach-Zehnder interferometer (MZI) is a device to detect the variation of the relative phase shift between two beams which are usually split from a single source. In optomicrofluidic devices, a MZI structure is typically integrated into an optical waveguide as shown in Figure 1. The signal is first coupled into the waveguide, and then split into two arms. One arm is a reference arm to compare the phase difference, and the other arm is used to sense the phase changes due to the variation of surround environmental parameters such as temperature (Dumais et al., 2008; Crespi et al., 2010), concentration (Lapsley et al., 2011), and refractive index (Densmore et al., 2008).

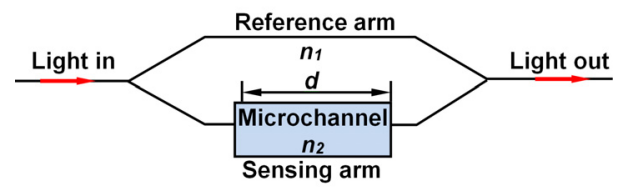

Figure 1. Schematic illustration of an opto-microfluidic MZI.

The output light intensity can be expressed as follow:

$I=I_{1}+I_{2}+2 \sqrt{I_{1} I_{2}} \cos (\delta \varphi)$

where $I$ is the output intensity, $I_{1}$ and $I_{2}$ are the intensities of the beams in the two branches, and $\delta \varphi$ is the phase difference of the two beams.

The phase difference is

$\delta \varphi=\frac{2 \pi\left(n_{1}-n_{2}\right) d}{\lambda}$

where $d$ is the length of the microchannel, $\lambda$ is the light wavelength, $n_{1}$ and $n_{2}$ are the refractive index of the materials in the two branches, respectively.

The schematic illustration of our MZI structure is depicted in Figure 2 (a). A waveguide with a discontinuous core is designed with the light coupled into the core from a taped SMF. When the light propagates into a gap, part of the light is recoupled into the core, and the other part of light is scattered into the cladding. Then the light propagates along two different paths either the core or the cladding. A SMF collects the light comes out from the core and the cladding to generate interference. In this design, the core works as the reference arm and the cladding acts as the sensing arm. Two light paths are integrated into one simple waveguide structure which is super compact compared with typical MZI structures. Figure 2(b) shows a COMSOL simulation of light propagating in a MZI structure with a gap length $l_{\mathrm{g}}$ of $200 \mu \mathrm{m}$ and a core width of $4 \mu \mathrm{m}$ at the wavelength of $1561 \mathrm{~nm}$. After the light passes the gap, the beams propagating along the cladding and core can be clearly observed.

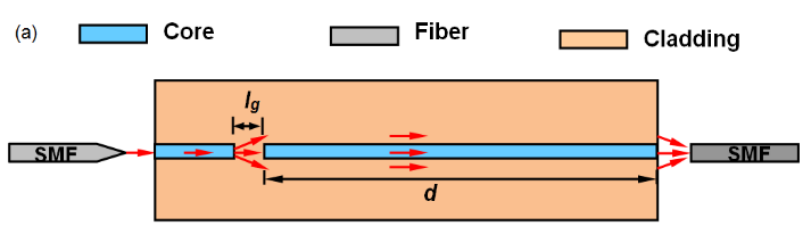

(b)

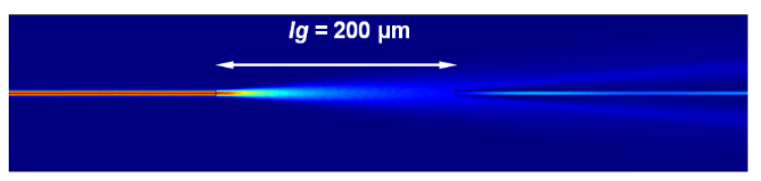

Figure 2. (a) Schematic illustration of a MZI structure with a discontinuous core; (b) Simulation of light propagation in a MZI structure with a gap length of $200 \mu \mathrm{m}$ and a core width of $4 \mu \mathrm{m}$ at the wavelength of $1561 \mathrm{~nm}$.

\subsection{Device Fabrication}

Figure 3 illustrates a typical microfabrication system with a femtosecond laser which is used in this study. The Ti: sapphire femtosecond laser with wavelength and repetition rate of $800 \mathrm{~nm}$ and $80 \mathrm{MHz}$, respectively, is focused on a sample by an objective lens $(20 \times, 0.46 \mathrm{NA})$. A variable attenuator, consisting of a half wave plate and a polarizer, is placed in the path of the beam to control and continuously adjust the output power of the laser. A shutter triggered by a computer program is used to control the exposure time of the sample to laser irradiation. A power meter monitors the change of the laser power in real time through a beam splitter.

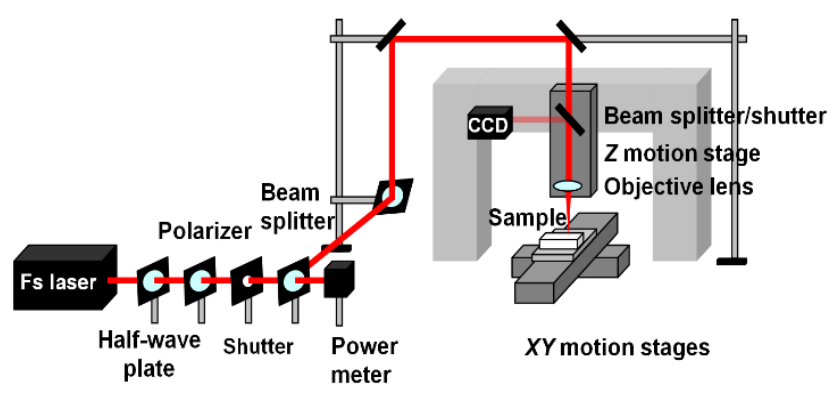

Figure 3. Schematic illustration of a microfabrication system with a femtosecond laser.

Figure 4 shows the fabrication processes of a MZI chip. First, the photoresist material SU-8 2 (Microchem $\left.{ }^{\circledR}\right)(n=1.575$ 
at $1550 \mathrm{~nm}$ ) is spin-coated and dried on a pre-cleaned glass substrate. Then the glass slide is put on the $X, Y, Z$ translation stages $\left(\right.$ Aerotech $\left.{ }^{\circledR}\right)$ which are controlled by a computer. A femtosecond laser (67 fs, $1.6 \mathrm{~nJ}$ pulses) is focused on the SU-8 2 film. By moving the $X, Y, Z$ translation stages, a discontinuous core is written on the film. After baking and developing processes, the discontinuous core structure is shown on the glass slide. Photoresist SU-8 3050 (Microchem $\left.{ }^{\circledR}\right)(n=1.559$ at $1550 \mathrm{~nm}$ ) is spin-coated and dried on the glass substrate again and exposed with an ultraviolet (UV) light through a metal mask. After the second baking and developing step, the cladding is shown on the glass slide. A PDMS microchannel is duplicated by the soft lithography technique, punched access holes with a needle, and bonded with the waveguide via oxygen plasma treatment (PDC-001, Harrick Plasma). The glass substrate is cut into a small piece and inserted capillary to generate a MZI chip. The cross section of the core is usually $4.15 \mu \mathrm{m} \times$ $3.20 \mu \mathrm{m}$ (width $\times$ height), and the cladding size is $125.00 \mu \mathrm{m}$ $\times 10.00 \mu \mathrm{m}$. Figure 5 (a) shows a morphology of a waveguide with a discontinuous core. The length of the gap is $200.00 \mu \mathrm{m}$. Figure 5 (b) presents a morphology of a waveguide covered by a microchannel with a width of $1 \mathrm{~mm}$. Figure 5 (c) is a photo of the MZI chip with a chip length of $2.70 \mathrm{~cm}$ and a microchannel length of $1.60 \mathrm{~cm}$. A taped SMF with a focused spot size of $2.50 \mu \mathrm{m}\left(\mathrm{OZ}^{\circledR}\right.$ optics) couples light from an $\mathrm{Er}^{3+}$ dual-band broadband source $(1520 \mathrm{~nm}-1620 \mathrm{~nm})$ into the core via butt coupling method. Because the size of the core is smaller than the core diameter of the single-mode fiber $(10.00 \mu \mathrm{m}$ corning $\mathbb{}$ SMF-28e), a SMF can simultaneously collect the light comes out from the core and cladding. Figure 5 (d) presents a near field image of the transmission light obtained by a CCD camera (Hamamatsu camera system) in which the bright dot in the middle is the light coming from the core, whereas the long bright line is the light coming from the cladding.

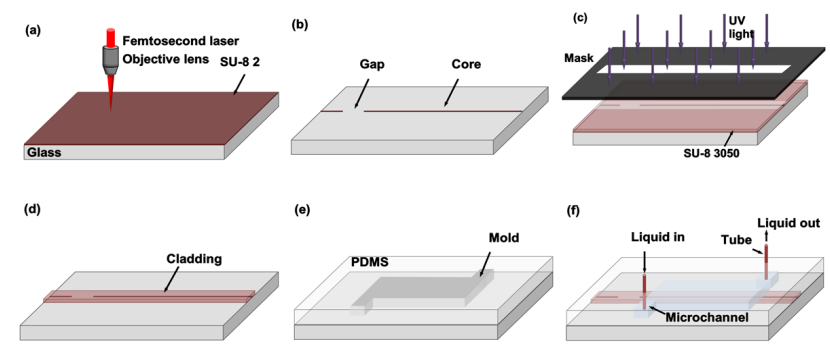

Figure 4. Procedures for MZI chip fabrication: (a) Femtosecond laser writing on the SU-8 2 film; (b) Discontinuous core; (c) Cladding fabrication with an UV light; (d) Waveguide with a discontinuous core; (e) PDMS microchannel fabrication; (f) MZI chip.

In this case, the Equation (2) changes to:

$\delta \varphi=\frac{2 \pi\left(n_{e f f-c o}-n_{e f f-c l}\right) d}{\lambda}=\frac{2 \pi \Delta n_{e f f} d}{\lambda}$

where $n_{\text {eff-co }}$ is the effective RI of the core, $n_{\text {eff-cl }}$ is the effective RI of the cladding, $\Delta n_{\text {eff }}$ is the RI difference of the core and cladding, and $d$ is the length of the sensing arm.

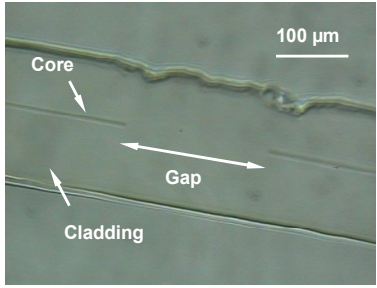

(a)

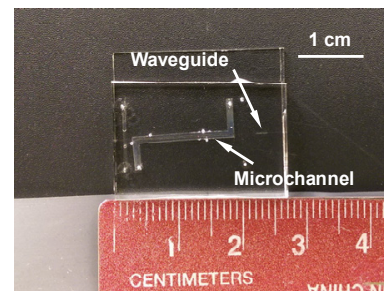

(c)

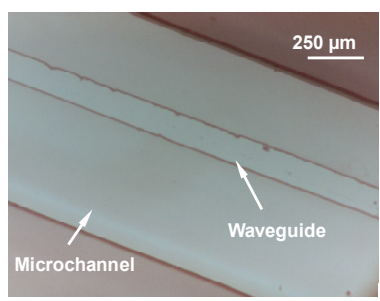

(b)

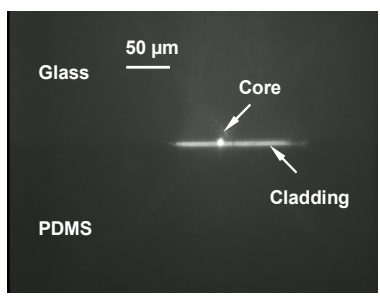

(d)
Figure 5. (a) Morphology of a waveguide with a discontinueous core; (b) Morphology of the waveguide covered by a microchannel; (c) MZI chip; (d) Near field image of the transmission light obtained by a CCD camera.

When the phase difference satisfies the following condition:

$\delta \varphi=2 m \pi$

where $m$ is the order of the MZI.

The attenuation peak or valley wavelength $\lambda_{\mathrm{m}}$ can be expressed as:

$\lambda_{m}=\frac{\Delta n_{e f f} d}{m}$

Liquids with different RIs can be injected into the microchannel. As a result, the effective RI of the cladding varies accordingly. However, the effective RI of the SU-8 core is hardly affected by the liquid. Therefore, Equation (5) can be shown as:

$$
\begin{aligned}
\delta \lambda_{m, n} & =\lambda_{m, n^{\prime}}-\lambda_{m, n}=\frac{\left(\Delta n_{e f f, n} d+\delta n_{e f f, n} l\right)}{m}-\frac{\Delta n_{e f f, n} d}{m} \\
& =\frac{\delta n_{\text {eff }, n} l}{m}=\frac{\delta n_{e f f, n} \lambda}{\Delta n_{\text {eff }, n}} \frac{l}{d}
\end{aligned}
$$

where $\delta n_{\text {eff }, n}=n_{\text {eff }-c l}^{\prime}-n_{\text {eff }-c l}$, and $l$ is the length of the microchannel.

If the environmental temperature of the waveguide rises, both the effective RIs of the cladding (SU-8 3050) and the core (SU-8 2) modes change to different extents $\left(\delta n_{\text {eff,T }}\right)$ due to the fact that the cladding and core have different thermo-optic coefficients. The attenuation peak wavelength shift $\delta \lambda_{m, T}$ is:

$$
\begin{aligned}
\delta \lambda_{m, T} & =\lambda_{m, T^{\prime}}-\lambda_{m, T} \\
& =\frac{\left(\Delta n_{\text {eff }, T}+\delta n_{\text {eff }, T}\right) d}{m}-\frac{\Delta n_{\text {eff }, T} d}{m}=\frac{\delta n_{\text {eff }, T} d}{m}
\end{aligned}
$$


where $\delta n_{\text {eff }, \mathrm{T}}=\left(d n / d T_{\text {core }}-d n / d T_{\text {cladding }}\right) T d n / d T$ is the thermo-optic coefficient of the material. ssed as:

Therefore, the shift in the peak wavelength can be expre-

$$
\begin{aligned}
\delta \lambda_{m, T} & =\frac{\left(\frac{d n}{d T_{\text {core }}}-\frac{d n}{d T_{\text {cladding }}}\right) d}{m} T \\
& =\frac{\left(\frac{d n}{d T_{\text {core }}}-\frac{d n}{d T_{\text {cladding }}}\right) \lambda}{\Delta n_{\text {eff }, T}} T
\end{aligned}
$$

\section{Results and Discussion}

A chip with a gap length of $200.00 \mu \mathrm{m}$ is used to measure the refractive index and temperature. The core size is $4.15 \mu \mathrm{m}$ $\times 3.20 \mu \mathrm{m}$, and the cladding size is $125.00 \mu \mathrm{m} \times 9.88 \mu \mathrm{m}$. The sensing arm is $24.29 \mathrm{~mm}$ and the microchannel has a size of $16.00 \mathrm{~mm} \times 1.00 \mathrm{~mm} \times 75.00 \mu \mathrm{m}$ (length $\times$ width $\times$ height $).$ Figure 6 shows a transmission spectrum in the range of 1520 $\mathrm{nm} \sim 1620 \mathrm{~nm}$ with salient interference patterns. For temperature sensing, the chip is placed on a small hotplate, and heated step by step. Transmission spectra are recorded and compared. Figure 7 presents the peak shift (red shift) at different temperatures, which exhibits a sensitivity of $0.519 \mathrm{~nm} /{ }^{\circ} \mathrm{C}$. By maintaining the temperature of hotplate at $20^{\circ} \mathrm{C}$, saline solutions are infused into the microchannel one by one. Figure 8 shows the peak shift (blue shift) at different RI and the dependence of the peak shift on refractive index /salinity with a refractive index sensitivity of $-215.744 \mathrm{~nm} / \mathrm{RIU}$.

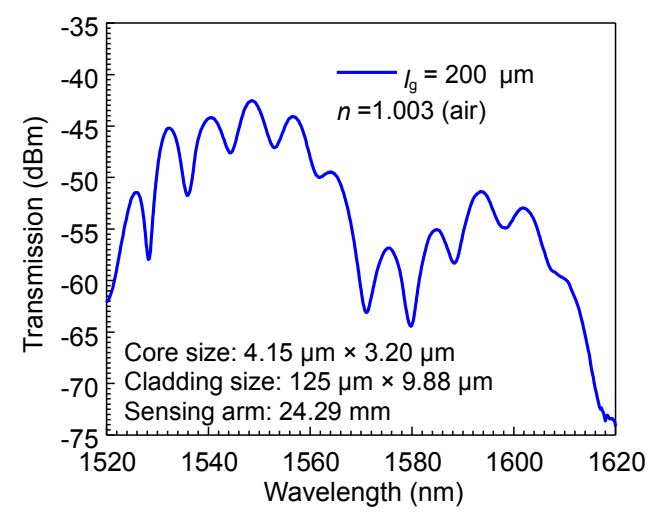

Figure 6. Transmission spectrum at the room temperature.

Following the sensing response with simultaneous variations in temperature and salinity, the total wavelength shift can be expressed as:

$$
\Delta \lambda=0.519 \Delta T-215.744 \Delta n
$$

where $\Delta T$ is the change of the temperature, and $\Delta n$ is the change of the refractive index. Since the wavelength shift exhibits a strong dependence on temperature, refractive index/salinity sensing must be accompanied by a temperature calibration in order to obtain precise results. The final RI of the saline solution can be calculated by Equation (9) if the temperature is known.
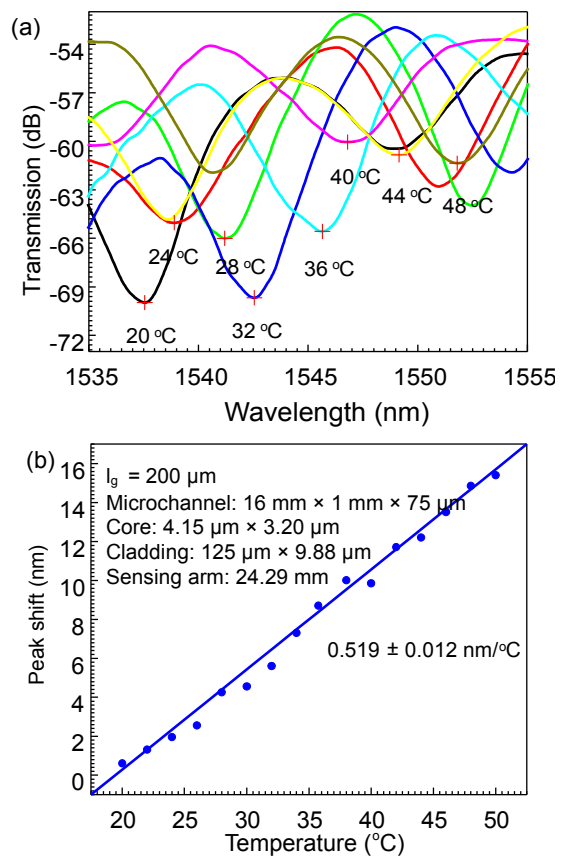

Figure 7. Temperature sensing: (a) Transmission spectra at different temperatures; (b) Dependence of the peak shift on temperature.
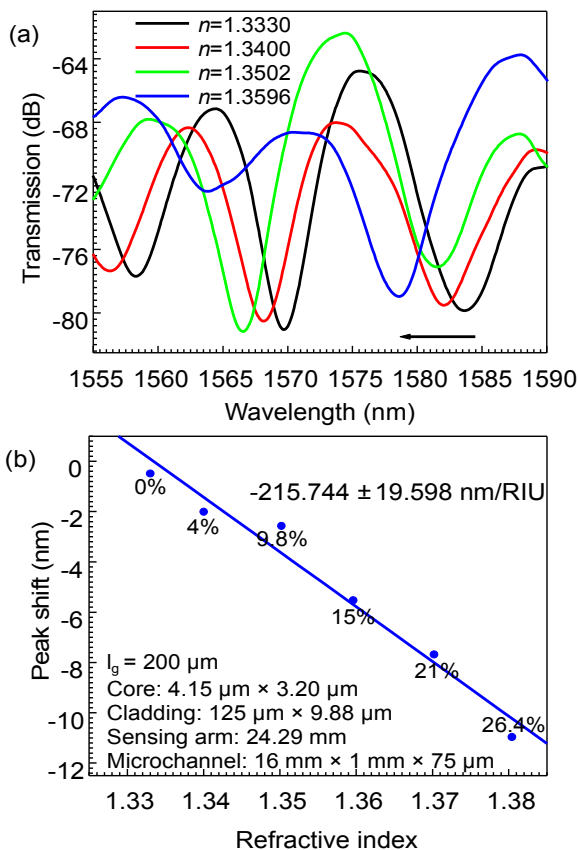

Figure 8. Refractive index sensing: (a) Transmission spectra at different RIs; (b) Dependence of the peak shift on refractive index/salinity. 


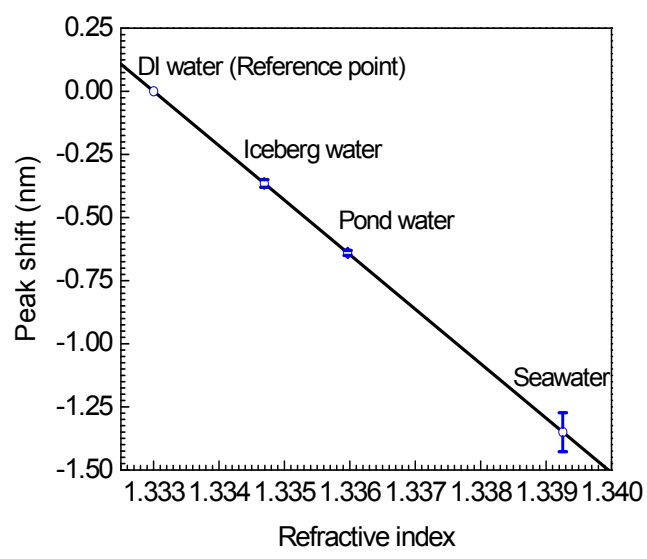

Figure 9. Refractive index measurement of different water samples.

In order to prove the validity of the chip, water samples are introduced into the chip, including melted iceberg water, pond water, and sea water. By maintaining the temperature of hotplate at $20^{\circ} \mathrm{C}$, distilled water is first infused into the chip for reference, and then water samples are injected into the microchannel. Figure 9 shows the experimental results of these samples. The RI of iceberg is about 1.3347 which is a bit higher than DI water. The RI of the pond water is 1.3360 . The RI of the seawater is about 1.3393. By calculation following the method discussed by Quan (Quan et al., 1995), the salinity is about $32.578 \%$, which is reasonable for the seawater.

\section{Conclusions}

In summary, we have successfully designed and fabricated an opto-microfluidic MZI sensor based on a waveguide with a discontinuous core. Temperature and refractive/salinity measurement have been achieved. The temperature and refractive index sensitivities are $0.159 \mathrm{~nm} /{ }^{\circ} \mathrm{C}$ and $-215.744 \mathrm{~nm} / \mathrm{RIU}$, respectively, which are much higher than those of fiber-optic sensors $\left(0.0102 \mathrm{~nm} /{ }^{\circ} \mathrm{C}\right.$ and $0.0165 \mathrm{~nm} / \mathrm{M}$ in Men et al., 2008; $0.029 \mathrm{~nm} /{ }^{\circ} \mathrm{C}$ and $0.069 \mathrm{~nm} / \mathrm{ppt}$ in Wang et al., 2006). This device can be applied to measure any solution with a refractive index smaller than 1.559, which is the refractive index of the cladding material. Different water samples are tested using this chip with good agreement, which demonstrates the practicability of the opto-microfluidic devices for in situ salinity monitoring of sea water with high sensitivity, accuracy and low cost.

Acknowledgments. The authors thank Natural Sciences and Engineering Research Council of Canada (NSERC), Canada Research Chairs Program, Canada Foundation for Innovation, the Province of Newfoundland and Labrador, and the Memorial University of Newfoundland on the support of research infrastructure.

\section{References}

Chin, L.K., Liu, A.Q., Zhang, J.B., Lim, C.S., and Soh, Y.C. (2008). An on-chip liquid tunable grating using multiphase droplet micro- fluidics. Appl. Phys. Lett., 93(16), 3332-3339. http://dx.doi.org/10. 1063/1.3009560

Choi, H.Y., Mudhana, G., Park, K.S., Peak, U.C., and Lee, B.H. (2010). Cross-talk free and ultra-compact fiber optic sensor for simultaneous measurement of temperature and refractive index. Opt. Express, 18(1), 141-149. http://dx.doi.org/10.1364/OE.18.000141

Crespi, A., Gu, Y., Ngamsom, B., Hoekstra, H.J.W.M., Dongre, C., Pollnau, M., Ramponi, R., Vlekkert, H.H., Watts, P., Cerullo, G., and Osellame, R. (2010). Three-dimensional Mach-Zehnder interferometer in a microfluidic chip for spatially-resolved label-free detection. Lab Chip, 10(9), 1167-1173. http://dx.doi.org/10.1039/b9200 $62 b$

Dai, D. (2009). Highly sensitive digital optical sensor based on cascaded high-Q ring-resonators. Opt. Express, 17(26), 23817-23822. http://dx.doi.org/10.1364/OE.17.023817

Densmore, A., Xu, D.X., Janz, S., Waldron, P., Mischki, T., Lopinski, G., Delâge, A., Lapointe, J., Cheben, P., Lamontagne, B., and Schmid, J.H. (2008). Spiral-path high-sensitivity silicon photonic wire molecular sensor with temperature-independent response. Opt. Lett., 33(6), 596-598 .http://dx.doi.org/10.1364/OL.33.000596

Dumais, P., Callender, C.L., Noad, J.P., and Ledderhof, C.J. (2008). Integrated optical sensor using a liquid-core waveguide in a MachZehnder interferometer. Opt. Express, 16(22), 18164-18172. http:// dx.doi.org/10.1364/OE.16.018164

Eftekhari, F., Escobedo, C., Ferreira, J., Duan, X., Girotto, E.M., Brolo, A.G., Gordon, R., and Sinton, D. (2009). Nanoholes as nanochannels: flow-through plasmonic sensing. Anal. Chem., 81(11), 43084311. http://dx.doi.org/10.1021/ac900221y

Forsythe ,K.W., Irvine, K.N., Atkinso, D.M., Perrelli, M., Aversa, J.M., Swales, S.J., Gawedzki, A., and Jakubek, D.J. (2015). Assessing Lead Contamination in Buffalo River Sediments. J. Environ. Inf., 26(2), 106-111.

Homola, J., Čtyroký, J., Skalský, M., Hradilová, J., and Kolářová, P. (1997). A surface plasmon resonance based integrated optical sensor. Sensors Actuators B: Chem., 39(1-3), 286-290. http://dx.doi.org/10. 1016/S0925-4005(97)80220-1

Lapsley, M.I., Chiang, I.K., Zheng, Y.B., Ding, X., Mao, X., and Huang, T.J. (2011). A single-layer, planar, optofluidic Mach-Zehnder interferometer for label free detection. Lab Chip, 11(10), 17951800. http://dx.doi.org/10.1039/c0lc00707b

Lawson, K. and Larson, N.G. (2001). CTD. In: Steele J. H., Thorpe S. A., Turekian K. K. (eds.), Encyclopedia of Ocean Sciences, Vol 1, Academic Press Inc Publishing, pp. 579-588. http://dx.doi.org/10.1 006/rwos.2001.0324

Li, B., Jiang, L., Wang, S., Tsai, H., and Xiao, H. (2011). Femtosecond laser fabrication of long period fiber gratings and applications in refractive index sensing. Opt. Laser Technol., 43(8), 1420-1423. htt p://dx.doi.org/10.1016/j.optlastec.2011.04.011

Lor K.P., Liu, Q., and Chiang, K.S. (2005). UV-written long-period gratings on polymer waveguides. IEEE Photonics Technol. Lett., 17(3), 594-596. http://dx.doi.org/10.1109/LPT.2004.840918

Men, L., Lu, P., and Chen, Q. (2008). A multiplexed fiber Bragg grating sensor for simultaneous salinity and temperature measurement. J. Appl. Phys., 103(5). http://dx.doi.org/10.1063/1.2890156

Nguyen, L.V., Vasiliev, M., and Alameh, K. (2011). Three-wave fiber Fabry-Pérot interferometer for simultaneous measurement of temperature and water salinity of seawater. IEEE Photonics Technol. Lett., 23(7), 450-452. http://dx.doi.org/10.1109/LPT.2011.2109057

Quan, X. and Fry, E.S. (1995). Empirical equation for the index of refraction of seawater. Appl. Opt., 34(18), 3477-3480. http://dx.doi. org/10.1364/AO.34.003477

Ren, L., Wu, X., Li, M., Zhang, X., Liu, L., and Xu, L. (2012). Ultrasensitive label-free coupled optofluidic ring laser sensor. Opt. Lett., 37 (18), 3873-3875. http://dx.doi.org/10.1364/OL.37.003873

Schueller, O.J.A., Duffy, D.C., Rogers, J.A., Brittain S.T., and Whitesides G.M. (1999). Reconfigurable diffraction gratings based on 
elastomeric microfluidic devices. Sensors Actuators A: Phys., 78(23), 149-159. http://dx.doi.org/10.1016/S0924-4247(98)00242-8

Shen, Z.Y., Chen, L., and Liao, Q., (2015). Effect of rainfall measurement errors on nonpoint-dource pollution model uncertainty. J. Environ. Inf., 26(1), 14-26. http://dx.doi.org/10.3808/jei.2014002 71

Shu, X., Gwandu, B.A.L., Liu, Y., Zhang, L., and Bennion, I. (2001). Sampled fiber Bragg grating for simultaneous refractive-index and temperature measurement. Opt. Lett., 26(11), 774-776. http://dx.doi. org/10.1364/OL.26.000774

Tan, X., Xia, X.L., Li, S.Y., and Zhang, Q.F.. (2015). Water quality characteristics and integrated assessment based on multistep correlation analysis in the Danjiangkou reservoir, China. J. Environ. Inf., 25(1), 60-70. http://dx.doi.org/10.3808/jei.201500296

Tian, Z., Yam, S.S.H., Barnes, J., Bock, W., Greig, P., Fraser, J.M., Loock, H.P., and Oleschuk, R.D. (2008). Refractive index sensing with Mach-Zehnder interferometer based on concatenating two single-mode fiber tapers, IEEE Photonics Technol. Lett., 20(8), 626 -628. http://dx.doi.org/10.1109/LPT.2008.919507

Urquhart, E.A., Zaitchik, B.F., Guikema, S.D., Haley, B.J., Taviani, E., Chen, A., Brown, M.E., Huq, A., and Colwell, R.R. (2015). Use of environmental parameters to model pathogenic vibrios in Chesapeake Bay. J. Environ. Inf., 26(1), 1-13. http://dx.doi.org/10.3808/jei. 201500307

Wang, Y.P., Wang, D.N., and Jin, W. (2006). CO2 laser-grooved long period fiber grating temperature sensor system based on intensity modulation. Appl. Opt., 45(31), 7966-7970. http://dx.doi.org/10.13 64/AO.45.007966
Wang, Y., Yang, M., Wang, D.N., Liu, S., and Lu, P. (2010). Fiber inline Mach-Zehnder interferometer fabricated by femtosecond laser micromachining for refractive index measurement with high sensitivity. J. Opt. Soc. Am. B, 27(3), 370-374. http://dx.doi.org/10.1364 JJOSAB.27.000370

Xiao, W.H., Wang, J.H., Huang, Y.H., Sun, S.C., and Zhou, Y.Y. (2015) An approach for estimating the nitrobenzene (NB) emission effect in frozen rivers: A case study of nitrobenzene pollution in the Songhua River, China. J. Environ. Inf., 26(2), 140-147.

Yebo, N.A., Lommens, P., Hens, Z., and Baets, R. (2010). An integrated optic ethanol vapor sensor based on a silicon-on-insulator microring resonator coated with a porous $\mathrm{ZnO}$ film. Opt. Express, 18(11), 11859-11866. http://dx.doi.org/10.1364/OE.18.011859

Yu, J.Q., Yang, Y., Liu, A.Q., Chin, L.K., and Zhang, X.M. (2010). Microfluidic droplet grating for reconfigurable optical diffraction. Opt. Lett., 35(11), 1890-1892. http://dx.doi.org/10.1364/OL.35.001 890

Yuan, L., Zhou, L., and Wu, J. (2000). Fiber optic temperature sensor with duplex Michleson interferometric technique. Sensors Actuators A: Phys., 86(1-2), 2-7. http://dx.doi.org/10.1016/S0924-4247(0 0)00357-5

Zhang, D., Men, L., and Chen, Q. (2011a). Microfabrication and applications of opto-microfluidics sensors, Sensors, 11(5), 5360-5382. ht tp://dx.doi.org/10.3390/s110505360

Zhang, X., Ren, L., Wu, X., Li, H., Liu, L., and Xu, L. (2011b). Coupled optofluidic ring laser for ultrahigh-sensitive sensing. Opt. Express, 19(22), 22242-22247. http://dx.doi.org/10.1364/OE.19.02224 